\title{
Assessing Students' Knowledge on WASH-Related Diseases
}

\author{
Khaldoon A. Mourad ${ }^{1, *(D)}$, Vincent Habumugisha ${ }^{2}$ and Bolaji F. Sule 3 \\ 1 Faculty of Social Sciences, Centre for Middle Eastern Studies, Lund University, 22100 Lund, Sweden \\ 2 Pan African University Institute of Water and Energy Sciences Including Climate Change, \\ B.P. 119 Pôle Chetouane, Tlemcen 13000, Algeria; vincenthaba@yahoo.fr \\ 3 Department of Water Resources \& Environmental Engineering, University of Ilorin, P.M.B 1515, \\ Ilorin 240003, Nigeria; bfsuleiman@gmail.com \\ * Correspondence: khaldoon.mourad@cme.lu.se
}

Received: 18 April 2019; Accepted: 6 June 2019; Published: 10 June 2019

\begin{abstract}
Water-, sanitation-, and hygiene-related diseases are killing many people each year in developing countries, including Rwanda, and children under the age of five are the most vulnerable. This research assessed human waste disposal practices, knowledge on diseases caused by contact with human faeces, and knowledge on causes and prevention of selected WASH-related diseases. One thousand one hundred and seventy-three students were interviewed out of 2900 students. The results showed, regarding students' waste disposal practices, that $96.3 \%$ use latrines, $20.5 \%$ practice open defecation in bushes, and 3.2\% defecate in water bodies. Regarding knowledge on diseases caused by contact with human faeces, $56.9 \%$ responded that they were aware of cholera, $26.5 \%$ of diarrhoea, $2.2 \%$ of dysentery, $0.3 \%$ of malaria, $0.1 \%$ of shigellosis, and $3.8 \%$ of typhoid. The majority of the respondents, between 50-99\%, could not identify the main causes of the WASH-related diseases. This paper also showed that students lack health knowledge in regard to WASH-related diseases' causes and prevention. Therefore, the provision of water and sanitation infrastructures should go with the provision of health education on how to avoid these diseases and possible ways to improve the well-being of the students both at home and in their various schools.
\end{abstract}

Keywords: Rwanda; sanitation; hygiene; education; assessment; waterborne diseases

\section{Introduction}

Water, sanitation, and hygiene term (WASH) represents a growing movement focusing on improving quality of life by reducing WASH-related diseases [1]. Some of the WASH-related diseases are presented below:

(1) Diarrhoea, which is usually caused by enterotoxigenic Escherichia coli [2]. Diarrhoea is responsible for about $21 \%$ of all under-five deaths [3]; about three-quarters of a million children die from diarrhoea every year [4]. Inadequate sanitation, hygiene, or access to safe water increase the incidence of diarrhoea diseases and deaths, which mostly occur in developing countries, including most African countries [5-7].

(2) Cholera is caused by the bacterium Vibrio cholera and is considered a major problem in Africa and Asia. Cholera causes diarrhoea and severe dehydration; sources of infections include standing water, seafood, grains, and unpeeled fruit and vegetables [8]. Overcrowded communities with poor sanitation and unsafe drinking water supplies are more vulnerable to cholera. If untreated, 50\% of people with severe cholera will die, but prompt and adequate treatment reduces deaths from severe cholera to less than 1\% of cases [5]. Many countries at Sub-Saharan Africa are broadly affected by many cholera cases [9]. 
(3) Trachoma is an infection caused by Chlamydia trachomatis that affects the eyes and may result in blindness. Trachoma has caused the visual impairment of 1.8 million people, with its impacts mostly occurring in developing countries, as poverty, crowded living conditions, and poor sanitation help in spreading the disease [10].

(4) Shigellosis is an intestinal disease caused by a group of bacteria known as Shigella and can be stopped by careful handwashing with soap. Infected people may develop diarrhoea, fever, and stomach cramps [11]. Bowen [12] argued that the risk of infection caused by Shigella spp. was highest for people traveling to Africa.

(5) Typhoid is caused by Salmonella typhi and is usually spread through contaminated water and food. Urbanization and climate change have the potential to increase the global burden of typhoid, which kills around 150,000 people every year [13].

(6) Malaria is on the list of Acquired Immunodeficiency Syndrome AIDS-related opportunistic infections and the highest rates occur in individuals infected with human immunodeficiency virus (HIV) [14]. In pregnant women, the co-infection with malaria and HIV is associated with anaemia, low birth weight, and increased risk of infant mortality to a greater extent than infection with either disease alone [15]. Malaria mortality is usually higher in low-income countries, such as most of the African counties [16]. Malaria is a vector-borne disease that requires better water resources management to reduce its transmission [17].

Improving water, sanitation, and hygiene practices helps in reducing the spread of waterborne diseases [18]. Moreover, ensuring a hygienic environment, clean water, and adequate sanitation can prevent infections associated with HIV/AIDS [19]. The United Nations (UN) identified critical problems associated with WASH-related diseases, especially in developing countries, including those in Africa. Therefore, the United Nations' Sustainable Development Goal 6: "Ensure access to water and sanitation for all", aimed at solving these issues by providing safe water and sanitation for all by 2030 because the better management of fresh water and sanitation are the pillars of human health, environmental sustainability, and economic prosperity [20].

Although Rwanda met the Millennium Development Goals (MDGs), the treated wastewaters do not meet the national standards due to poor governmental monitoring, which is considered a big challenge to achieve the Sustainable Development Goals (SDGs) in 2030 [21]. Rwanda faces many barriers to achieving improved sanitation, including the high population density in the cities, the lack of space for latrines in some areas, such as Kigali city, and the costs [22]. The poor hygiene practices and lack of access to improved water and sanitation facilities in Rwanda increases WASH-related mortality and morbidity [23-25]. In 2016, the Rwanda Biomedical Centre confirmed the outbreak of non-bloody diarrhoea, typhoid, shigellosis, and cholera cases in Rwanda. According to the World Health Organization and Rwandan Biomedical Centre, flood dispersal of faecal contaminants, water shortages, poor sanitation and hygiene practices, and insufficient knowledge are among the key causes leading to increased risks of outbreaks of waterborne diseases such as cholera [26]. According to the Rwanda Biomedical Centre, from 2010 to 2017, seventeen cholera outbreaks were recorded, with a total of 420 cases and 6 deaths documented.

The main reasons for these outbreaks were drinking from Kivu Lake, poor hygiene, lack of latrines (many households shared one latrine), non-functional water taps, non-chlorinated water, and using surface water as a latrine [26,27].

This paper assesses students' knowledge on water-, sanitation-, and hygiene-related diseases in randomly selected rural and urban schools in Musanze District in Rwanda, with a focus on human waste disposal practices, diseases caused by contact with human faeces, and the causes and prevention of some WASH-related diseases. 


\section{Methods}

\subsection{Study Area}

Rwanda is surrounded by Uganda, Tanzania, and Burundi. Rwanda is divided into five provinces: City of Kigali, Eastern Province, Northern Province, Western Province, and Southern Province, each of which has three to eight districts [28]. This research was conducted in Musanze District, one of the five districts that make up Northern Province of Rwanda (Figure 1; [29]). The population of Musanze is about 370,000 and a total area of $530.4 \mathrm{~km}^{2}$ [30].

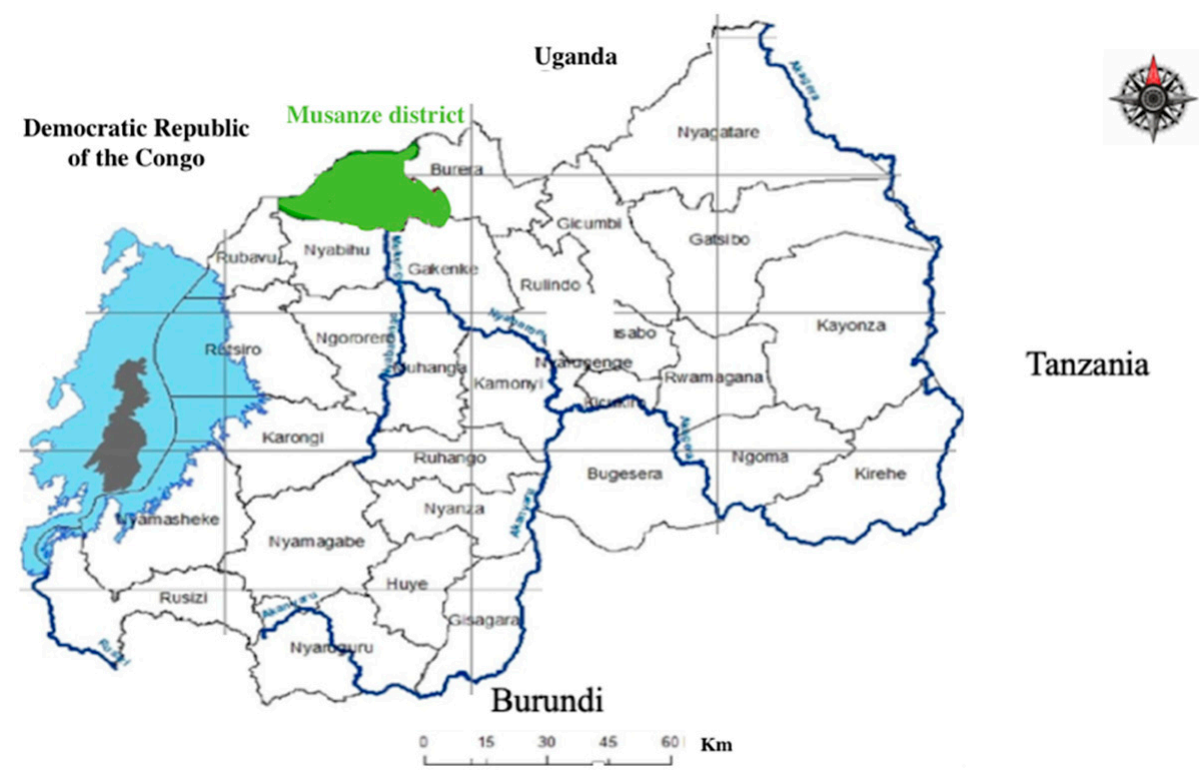

Figure 1. Rwanda and Musanze district location.

\subsection{Sample Size}

Students from six randomly selected schools (three rural and three urban), representing a total student population of 2900, were interviewed. The students' ages were between 12 and 15 years. Krejcie and Morgan's [31] table was used to select the sample size from each school, which presents an acceptable margin of error (about 3\%).

Krejcie and Morgan used the following formula to determine the sample size [32]:

$$
S=X^{2} N P(1-P) / d^{2}(N-1)+X^{2} P(1-P)
$$

where $S$ is the required sample size; $X^{2}$ is the table value of chi-square for one degree of freedom at the desired confidence level; $\mathrm{N}$ is population size; $\mathrm{P}$ is the population proportion; $\mathrm{d}$ is the degree of accuracy.

Table 1 presents the population size and location for each selected school. All samples were summed up to 1173 students. The data were analysed using Statistical Package of Social Sciences (SPSS) (IBM corporation, Armonk, NY, USA). 
Table 1. Schools' population and sample size.

\begin{tabular}{cccc}
\hline Name of School & Location of School & Population Size & Sample Size \\
\hline Esc. Musanze & Urban & 208 & 136 \\
GS ${ }^{1}$. Muhoza II & Urban & 695 & 248 \\
ESSA Ruhengeri & Urban & 140 & 103 \\
GS. Nyange & Rural & 570 & 226 \\
GS. Kampanga & Rural & 912 & 269 \\
GS. Gakoro & Rural & 375 & 191 \\
\hline Total & 2900 & 1173 \\
\hline & 1 G.S. Group School.
\end{tabular}

\subsection{Gender and Location}

The respondents were $56.6 \%$ females and $43.4 \%$ males. In general, there were more females in urban areas $(57.7 \%)$ compared to rural areas $(55.8 \%)$. Rural areas appeared to have more students $(58.4 \%)$ compared to urban areas $(41.7 \%)$ (Table 2$)$.

Table 2. Gender and locations for students.

\begin{tabular}{rrcccc}
\hline & & & \multicolumn{2}{c}{ Gender } & \multirow{2}{*}{ Total } \\
\cline { 3 - 4 } & & & Female & Male & \\
\hline \multirow{3}{*}{ Location of school } & \multirow{2}{*}{ Rural } & Count & 383 & 303 & 686 \\
& & $\%$ & $55.8 \%$ & $44.2 \%$ & $100 \%$ \\
& \multirow{2}{*}{ Urban } & Count & 281 & 206 & 487 \\
& & $\%$ & $57.7 \%$ & $42.3 \%$ & $100 \%$ \\
\multirow{2}{*}{ Total } & & Count & 664 & 509 & 1173 \\
& & $\%$ & $56.6 \%$ & $43.4 \%$ & $100 \%$ \\
\hline
\end{tabular}

\section{Results and Discussion}

\subsection{Type of Human Waste Disposal Used by Students}

The results showed that, overall, $96.3 \%$ of students used latrines as a method of human waste disposal. In rural areas, $97.7 \%$ used latrines, while $94.5 \%$ used latrines in urban areas. In regard to the students who used bush toilets as a method of human waste disposal, across both rural and urban schools, the results showed that $20.5 \%$ used open defecation in bushes, about $31.1 \%$ used open defecation in rural areas, while about $5.3 \%$ used open defecation in urban areas. On the other hand, the results showed that $3.2 \%$ of the students disposed their wastes into water bodies.

\subsection{Knowledge on Diseases Caused by Contact with Human Faeces}

Cholera, diarrhoea, dysentery, shigellosis, and typhoid are diseases connected to contact with human faeces. However, malaria is a water-related disease that is not related to human faeces.

In both rural and urban areas, students mentioned different diseases that they knew were caused by contact with human faeces. Across the schools, 56.9\% mentioned cholera, 26.5\% mentioned diarrhoea, $2.2 \%$ mentioned dysentery, $0.3 \%$ mentioned malaria, $0.1 \%$ mentioned shigellosis, $3.8 \%$ mentioned typhoid, and $10.1 \%$ had no idea. Cholera and diarrhoea were the most mentioned diseases in both rural and urban areas, while shigellosis and malaria were the least mentioned (Table 3). Table 3 also shows that, in general, students in urban areas had more knowledge than those living in rural areas. For example, the differences in the percentages were 5.7 and 7.3 regarding the knowledge of typhoid and diarrhoea, respectively. However, it was the opposite for cholera, with more rural students being knowledgeable of the disease than urban students. 
Table 3. Knowledge about diseases.

\begin{tabular}{rlccccccccc}
\hline & & & Cholera & Diarrhoea & Dysentery & Malaria & No Answer & \multicolumn{2}{c}{ Shigellosis Typhoid } & Total \\
\hline \multirow{5}{*}{ Location of school } & \multirow{2}{*}{ Rural } & Count & 417 & 161 & 13 & 0 & 84 & 1 & 10 & 686 \\
& & $\%$ & $60.8 \%$ & $23.5 \%$ & $1.9 \%$ & $0.0 \%$ & $12.2 \%$ & $0.1 \%$ & $1.5 \%$ & $100 \%$ \\
& \multirow{2}{*}{ Urban } & Count & 251 & 150 & 13 & 3 & 35 & 0 & 35 & 487 \\
& & $\%$ & $51.5 \%$ & $30.8 \%$ & $2.7 \%$ & $0.6 \%$ & $7.2 \%$ & $0.0 \%$ & $7.2 \%$ & $100 \%$ \\
\cline { 3 - 10 } & & Count & 668 & 311 & 26 & 3 & 119 & 1 & 45 & 1173 \\
& & $\%$ & $56.9 \%$ & $26.5 \%$ & $2.2 \%$ & $0.3 \%$ & $10.1 \%$ & $0.1 \%$ & $3.8 \%$ & $100 \%$ \\
\hline
\end{tabular}

\subsection{Knowledge on Selected WASH-Related Diseases}

\subsubsection{Causes}

Diarrhoea is a symptom of infection caused by a host of bacterial, viral, and parasitic pathogens living in water contaminated by human faecal and animal faecal matter from municipal sewage, septic tanks, and latrines. Therefore, drinking dirty water that is polluted by human faeces, poor sanitation, and improper hygiene are likely to result in diarrhoea. Amoebas also cause diarrhoea [33]. The bulk of students in both rural and urban areas had no knowledge about the causes of diarrhoea. About $0.2 \%$ mentioned that amoebas are the cause of diarrhoea. About $11.3 \%$ mentioned drinking dirty water, $15.3 \%$ mentioned poor sanitation and hygiene, while $73.1 \%$ did not know the causes of diarrhoea. Amoebas and drinking dirty water were mostly stated in both rural and urban schools.

Shigellosis is caused by Shigella bacteria. Most of the infections come from the stools or the soiled fingers of an infected person to the mouth of a healthy person. Therefore, contact with human faeces, water pollution by human faeces, and poor disposal of human faeces can result in shigellosis. The bulk of respondents had no idea about the causes of shigellosis. About $0.2 \%$ mentioned that it is caused by contact with human faeces, $0.2 \%$ responded that it is caused by polluted water, and $1.6 \%$ mentioned poor hygiene. However, $98 \%$ did not know what causes shigellosis.

Cholera is caused by the bacterium Vibrio cholera. People get infected with cholera after eating food or drinking water that has been infected by faeces of a cholera-infected person. Respondents mentioned food and water contaminated by human faeces (10.9\%) and Vibrio cholera (6.3\%). However, $82.8 \%$ did not know what causes cholera.

Typhoid is caused by Salmonella typhi. People are infected with Salmonella typhi via faecal-oral route from infected individuals to healthy individuals. Generally, students had little knowledge about what causes trachoma. Only $0.8 \%$ responded that it is caused by washing one's face with dirty water, while $99.2 \%$ did not know the cause. Eating contaminated food or water (4.9\%) and Salmonella typhi (3.8\%) were mentioned to be causes of typhoid. However, about $91.4 \%$ did not know the cause of typhoid.

Malaria is caused by plasmodium parasites and is spread when people are bitten by a malaria-infected Anopheles mosquito. Female Anopheles mosquitoes (58.4\%) and stagnant water around home $(0.4 \%)$ were stated to be causes of malaria. However, about $41.2 \%$ did not know the causes of malaria.

\subsubsection{Prevention}

Having knowledge in the prevention of WASH-related diseases is a key to having better health. About $15.8 \%$ of respondents mentioned drinking clean water as a way to prevent cholera, and $37.5 \%$ mentioned washing hands with soap and maintaining food hygiene to prevent diarrhoea diseases. About $26.5 \%$ stated draining stagnant water, using bed nets, and clearing bushes around the home as a way of preventing malaria. About $0.3 \%$ said that they can prevent shigellosis through washing hands with soap and prevention of contact with human faeces, while only $0.1 \%$ said that they can avoid swimming in dirty water to prevent trachoma, and about $2.6 \%$ said cleaning raw fruits and vegetables and using clean water is the way to prevent typhoid. However, about $17.1 \%$ did not have knowledge about how to prevent any of the stated diseases (Table 4). 
Table 4. Students' knowledge on WASH-diseases prevention methods.

\begin{tabular}{cccccccccc}
\hline & & Cholera & Diarrhoea & Malaria & No Knowledge & Shigellosis & Trachoma & Typhoid & Total \\
\hline \multirow{2}{*}{ Rural } & Count & 86 & 224 & 290 & 74 & 2 & 0 & 10 & 686 \\
& $\%$ & $12.5 \%$ & $32.7 \%$ & $42.3 \%$ & $10.8 \%$ & $0.3 \%$ & $0 \%$ & $1.5 \%$ & $100 \%$ \\
\multirow{2}{*}{ Urban } & Count & 99 & 216 & 21 & 127 & 2 & 1 & 21 & 487 \\
& $\%$ & $20.3 \%$ & $44.4 \%$ & $4.3 \%$ & $26.1 \%$ & $0.4 \%$ & $0.2 \%$ & $4.3 \%$ & $100 \%$ \\
\multirow{2}{*}{ Total } & Count & 185 & 440 & 311 & 201 & 4 & 1 & 31 & 1173 \\
& $\%$ & $15.8 \%$ & $37.5 \%$ & $26.5 \%$ & $17.1 \%$ & $0.3 \%$ & $0.1 \%$ & $2.6 \%$ & $100 \%$ \\
\hline
\end{tabular}

\section{Conclusions}

The promotion of health and hygiene in schools is essential for all students in order to support the Child-Friendly Schools program [34]. This study focused on assessing student knowledge regarding WASH-related diseases, causes, and prevention. Generally, the bulk of students surveyed used latrines as a method of human waste disposal, however, a small percentage of them used open defection in bushes and water bodies, which can cause the spread of diseases. Many students (10.1\%) did not know any disease caused by contact from human faeces, and this can affect their attitudes and practices toward open defecation in bushes and water bodies.

An above average number of respondents did not know the causes of diarrhoea, shigellosis, cholera, trachoma, and typhoid. This is a big problem, because they did not know what their practices and attitudes toward sanitation and hygiene may cause in relation to WASH-related diseases.

We conclude that knowledge on the causes and prevention of WASH-related diseases is very low, and only a very few students knew how to protect themselves and exercise disease prevention. Therefore, the government of Rwanda and partners in water, sanitation, and hygiene should focus not only on providing water and sanitation infrastructures, but also on health education that can raise students' awareness in regard to the need for individual clean practices and the related risks associated with WASH diseases. The education should be a way to stop open defecation in bushes and water bodies, by teaching students the health risks of diseases caused by contact with human faeces and also teaching students the causes and prevention of WASH-related diseases. This kind of education would result in positive changes in students' attitudes toward sanitation and hygiene practices. Health education should also include the proper use of sanitation and drinking water infrastructures.

Author Contributions: Methodology and field works: V.H. and B.F.S.; analyses: V.H. and B.F.S.; scientific literature and resources: K.A.M.; interviews, V.H. and B.F.S.; data: K.A.M. writing the original draft: K.A.M.; writing, reviewing, and editing: K.A.M.; supervision: K.A.M.; submission to an open access journal: K.A.M.

Funding: This research received no external funding.

Acknowledgments: We thank the Authority of Musanze District who approved this research. We also thank all the school directors, teachers, and students in Musanze District who devoted their time and efforts in data collection and providing responses, which helped in achieving the research objectives. Finally, support from Pan African University, PAWES, and the Swedish Strategic Research Area MECW at Lund University are acknowledged.

Conflicts of Interest: The authors declare no conflict of interest.

\section{References}

1. UNICEF. About WASH. Available online: https://www.unicef.org/wash/3942_3952.html (accessed on 22 May 2019).

2. Sack, R.B. Human diarrheal disease caused by enterotoxigenic Escherichia coli. Annu. Rev. Microbiol. 1975, 29, 333-353. [CrossRef]

3. Bryce, J.; Boschi-Pinto, C.; Shibuya, K.; Black, R.E. The Child Health Epidemiology Reference Group WHO estimates of the causes of death in children. Lancet 2005, 365, 1147-1152. [CrossRef]

4. Nicole, W. The WASH Approach: Fighting Waterborne Diseases in Emergency Situations. Environ. Health Perspect. 2015. [CrossRef]

5. World Health Organization. Water-Related Diseases. Available online: https://www.who.int/water_ sanitation_health/diseases-risks/diseases/diseasefact/en/ (accessed on 22 May 2019). 
6. Saeed, A.; Abd, H.; Sandstorm, G. Microbial aetiology of acute diarrhoea in children under five years of age in Khartoum, Sudan. J. Med. Microbiol. 2015, 64, 432-437. [CrossRef]

7. CIDRAP. Studies: Diarrheal Disease Rates Vary across Africa, World. Center for Infectious Disease Research and Policy, University of Minnesota: Minneapolis, MN, USA. Available online: http://www.cidrap.umn.edu/newsperspective/2018/09/studies-diarrheal-disease-rates-vary-across-africa-world (accessed on 5 June 2019).

8. Mayo Clink. Cholera. Available online: https://www.mayoclinic.org/diseases-conditions/cholera/symptomscauses/syc-20355287 (accessed on 5 June 2019).

9. Gaffga, N.H.; Tauxe, R.V.; Mintz, E.D. Cholera: A new homeland in Africa? Extern. Am. J. Trop. Med. Hyg. 2007, 77, 705-713. [CrossRef]

10. Boyd, K.; Jimenez, M.E. What is Trachoma. American Academy of Ophthalmology 2019, San Francisco, USA. Available online: https:/www.aao.org/eye-health/diseases/what-is-trachoma (accessed on 22 May 2019).

11. Centers for Disease Control and Prevention, National Center for Emerging and Zoonotic Infectious Diseases (NCEZID), Division of Foodborne, Waterborne, and Environmental Diseases (DFWED). Shigella—Shigellosis. 2018. Available online: https://www.cdc.gov/shigella/index.html (accessed on 22 May 2019).

12. Bowen, A. Infectious Diseases Related to Travel. Centers for Disease Control and Prevention, National Center for Emerging and Zoonotic Infectious Diseases (NCEZID), Division of Foodborne, Waterborne, and Environmental Diseases (DFWED), 2017. Available online: https://wwwnc.cdc.gov/travel/yellowbook/2018/infectiousdiseases-related-to-travel/shigellosis (accessed on 22 May 2019).

13. WHO. Typhoid. 2018. Available online: https://www.who.int/news-room/fact-sheets/detail/typhoid (accessed on 23 May 2019).

14. Di Gennaro, F.; Marotta, C.; Pizzol, D.; Chhaganlal, K.; Monno, L.; Putoto, G.; Saracino, A.; Casuccio, A.; Mazzucco, W. Prevalence and Predictors of Malaria in Human Immunodeficiency Virus Infected Patients in Beira, Mozambique. Int. J. Environ. Res. Public Health 2018, 15, 2032. [CrossRef]

15. Idemyor, V. Human immunodeficiency virus (HIV) and malaria interaction in sub-Saharan Africa: The collision of two Titans. HIV Clin. Trials 2007, 8, 246-253. [CrossRef]

16. Murray, C.J.; Rosenfeld, L.C.; Lim, S.S.; Andrews, K.G.; Foreman, K.J.; Haring, D.; Fullman, N.; Naghavi, M.; Lozano, R.; Lopez, A.D. Global Malaria mortality between 1980 and 2010: A systematic analysis. Lancet 2012, 379, 413-431. [CrossRef]

17. Australian Water Association. WASH Fact Sheet. NSW, Australia. Available online: https://www.awa.asn. au/AWA_MBRR/Publications/Fact_Sheets/WASH_Fact_Sheet.aspx (accessed on 5 June 2019).

18. Yaya, S.; Hudani, A.; Udenigwe, O.; Shah, V.; Ekholuenetale, M.; Bishwajit, G. Improving Water, Sanitation and Hygiene Practices, and Housing Quality to Prevent Diarrhea among Under-Five Children in Nigeria. Trop. Med. Infect. Dis. 2018, 3, 41. [CrossRef] [PubMed]

19. UNICEF for Every Child. Water, Sanitation and Hygiene. Available online: https://www.unicef.org/wash/ index_wes_related.html (accessed on 5 June 2019).

20. United Nations. Goal 6: Ensure Access to Water and Sanitation for All. 2017. Available online: https: //www.un.org/sustainabledevelopment/water-and-sanitation/ (accessed on 22 May 2019).

21. Kazora, A.S.; Mourad, K.A. Assessing the Sustainability of Decentralized Wastewater Treatment Systems in Rwanda. Sustainability 2018, 10, 4617. [CrossRef]

22. Tsinda, A.; Pamela, A.; Steve, P.; Katrina, C.; Jane, A.; Kenan, O.; Jonathan, C. Challenges to Achieving Sustainable Sanitation in Informal Settlements of Kigali, Rwanda. Int. J. Environ. Res. Public Health 2013, 10, 6939-6954. [CrossRef]

23. The United Nations in Rwanda. Social Protection, Water Sanitation and Hygiene. Available online: http://www. rw.one.un.org/what-we-do/human-development/social-protection-water-sanitation-and-hygiene (accessed on 23 May 2019).

24. Niyitegeka, T. Rubavu Puts Up Camp for Cholera Patients. 2016. Available online: http://en.igihe.com/news/ rubavu-puts-up-camp-for-cholera-patients.html (accessed on 23 May 2019).

25. Mukaneza, M.A.; Mukwaya, O. Impunzi Umunani Zaturutse Muri RDC Zagaragayeho Cholera. 2017. Available online: https://www.igihe.com/amakuru/u-rwanda/article/rubavu-impunzi-umunani-zaturutsemuri-rdc-zagaragayeho-cholera (accessed on 23 May 2019).

26. RBC. Rwanda Biomedical Center, Annual Reports. Available online: http://www.rbc.gov.rw/index.php?id=283 (accessed on 23 May 2019). 
27. Nyamusore, J. Cholera Outbreak Inventory, Seasonality and Risk Factors. Epidemic Surveillance and Response, 2015. Available online: http://www.rbc.gov.rw/fileadmin/user_upload/cholera_outbreak_ inventory_and_seasonality_august_2015-2.pdf (accessed on 23 May 2019).

28. Republic of Rwanda-Ministry of Local Government. Available online: http://minaloc.gov.rw/index.php?id=492 (accessed on 23 May 2019).

29. Maniriho, A.; Bizoza, A.R. Financial Benefit-Cost Analysis of Agricultural Production in Musanze District, Rwanda. Acad. Arena 2013, 5, 30-39.

30. Repubulika y'u Rwanda Intara y'Amajyaruguru Akarere ka Musanze. Available online: https://musanze. gov.rw/index.php?id=83 (accessed on 23 May 2019).

31. Krejcie, R.V.; Morgan, D.W. Determining Sample Size for Research Activities. Educ. Psychol. Meas. 1970, 30, $607-610$. [CrossRef]

32. Chuan, C.L.; Penyelidikan, J. Sample Size Estimation Using Krejcie and Morgan and Cohen Statistical Power Analysis: A Comparison. Available online: http://www.ipbl.edu.my/portal/penyelidikan/jurnalpapers/ jurnal2006/chua06.pdf (accessed on 22 May 2019).

33. Battikhi, M.N. Bloody diarrhoea cases caused by Shigella and amoeba in Jordan. New Microbiol. 2004, 27, $37-47$.

34. Clover, J. UNICEF's Child-Friendly Schools Initiative Aims to Improve Sanitation Facilities in Rwandan Schools. 2011. Available online: https://www.unicef.org/adolescence/rwanda_60191.html (accessed on 23 May 2019).

(C) 2019 by the authors. Licensee MDPI, Basel, Switzerland. This article is an open access article distributed under the terms and conditions of the Creative Commons Attribution (CC BY) license (http://creativecommons.org/licenses/by/4.0/). 